\title{
Mental health in hypertension: assessing symptoms of anxiety, depression and stress on anti-hypertensive medication adherence
}

\author{
Irene A Kretchy ${ }^{1,2^{*}}$, Frances T Owusu-Daaku ${ }^{1}$ and Samuel A Danquah ${ }^{3}$
}

\begin{abstract}
Background: Patients with chronic conditions like hypertension may experience many negative emotions which increase their risk for the development of mental health disorders particularly anxiety and depression. For Ghanaian patients with hypertension, the interaction between hypertension and symptoms of anxiety, depression and stress remains largely unexplored. To fill this knowledge gap, the study sought to ascertain the prevalence and role of these negative emotions on anti-hypertensive medication adherence while taking into account patients' belief systems.

Methods: The hospital-based cross-sectional study involving 400 hypertensive patients was conducted in two tertiary hospitals in Ghana. Data were gathered on patient's socio-demographic characteristics, anxiety, depression and stress symptoms, spiritual beliefs, and medication adherence.

Results: Hypertensive patients experienced symptoms of anxiety (56\%), stress (20\%) and depression (4\%). As a coping mechanism, a significant relation was observed between spiritual beliefs and anxiety $\left(x^{2}=13.352, p=0.010\right)$, depression $\left(x^{2}=6.205, p=0.045\right)$ and stress $\left(x^{2}=14.833, p=0.001\right)$. Stress among patients increased their likelihood of medication non-adherence [odds ratio $(\mathrm{OR})=2.42(95 \% \mathrm{Cl} 1.06-5.5), p=0.035$ ].

Conclusion: The study has demonstrated the need for clinicians to pay attention to negative emotions and their role in medication non-adherence. The recommendation is that attention should be directed toward the use of spirituality as a possible mechanism by which negative emotions could be managed among hypertensive patients.
\end{abstract}

Keywords: Hypertension, Negative emotions, Medication non-adherence, Spirituality, Ghana

\section{Background}

As disease burdens shift from infectious to noncommunicable diseases, hypertension is a principal precursor to cardiovascular diseases and a main cause of death globally $[1,2]$. About $80 \%$ of these deaths were recorded in low- and middle- income countries and projections indicate that the highest non-communicable mortality rates would be recorded in these countries by 2020 [3]. Hypertension affects approximately $25 \%$ of urban and $20 \%$ of rural Ghanaian populations [4] and $11 \%-42 \%$ of Africans

\footnotetext{
* Correspondence: iakretchy@yahoo.com

'Department of Clinical and Social Pharmacy, Faculty of Pharmacy and Pharmaceutical Sciences, Kwame Nkrumah University of Science and Technology, Kumasi, Ghana

${ }^{2}$ Department of Pharmacy Practice and Clinical Pharmacy, University of Ghana School of Pharmacy, College of Health Sciences, Legon, Ghana Full list of author information is available at the end of the article
}

[2,5-7]. A global hypertension prevalence of $26 \%$ is projected to ascend to $29 \%$ by the year 2025 [8].

Like patients with other chronic medical conditions, hypertensive patients experience many profound emotions which increase their risk for the development of mental health disorders particularly anxiety and depression $[9,10]$. Imperative to the management of hypertension is the need for patients to adhere to pharmacological and non-pharmacological therapies and these negative emotions may adversely influence their adherence behaviour [11].

Anxiety and lower adherence rates have been observed for asthma, heart failure, haemodialysis and contraceptive use [12-15], although Kim et al. [16] noticed greater adherence among the majority of their patients with anxiety disorder. 
Depression is a burdensome disease of global importance [17] and although prevalent, it is mostly undiagnosed in patients with hypertension [18]. Some relationship has been observed between depression and non-adherence to medical therapy $[19,20]$ and a high number of prescribed medications were listed as one of the contributing factors for the development of depressive symptoms in hypertension [21]. However not all studies successfully showed a relationship between depressive symptoms and adherence [14,22].

The stress of having a chronic medical condition may potentially influence medication adherence behaviour; yet, earlier studies on emotional determinants of adherence have largely focused on depression and anxiety $[12,14]$. In clinical settings, stress has repeatedly been used as a euphemism for negative emotions, particularly to address undesirable psychiatric diagnostic labelling [23]. Stress negatively influenced medication adherence behaviour in HIV/AIDS [24] and acute coronary syndrome [25]. Empirical evidence showed the importance of stress in the onset and worsening of essential hypertension [26], yet there is a dearth of information associating stress and medication adherence in hypertension management.

Drawing a causal relationship between anxiety, depression and stress, in hypertension and medication adherence may be difficult [19]; but on the other hand, overlooking the association may further decrease attempts to manage the burden of medication non-adherence. For Ghanaian patients with hypertension, this interaction between hypertension and symptoms of anxiety, depression and stress remains largely unexplored and incompletely understood in terms of its prevalence and effect on medication adherence. To fill this knowledge gap, the study sought to ascertain 1) whether hypertensive patients exhibited symptoms of anxiety, depression and stress; 2) whether individuals experiencing anxiety, depression and stress symptoms were more likely to be non-adherent than patients without these symptoms; and 3) whether patients' belief systems had a relationship with anxiety, depression and stress symptoms.

\section{Methods}

\section{Study design and setting}

A hospital-based cross-sectional study design was used. The study was carried out at the two major teaching hospitals in Ghana; Korle-Bu Teaching Hospital (KBTH), Accra and Komfo Anokye Teaching Hospital (KATH), Kumasi. The description of the study site has previously been reported [27].

\section{Participants}

Two hundred (200) hypertensive outpatients each were recruited from KBTH and KATH. Eligibility to participate in the study was based on the following: A diagnosis of hypertension only or hypertension with other co-morbid conditions, reporting prescription of at least one antihypertensive medication for a minimum of two months and an age of at least eighteen years. The sample did not include pregnant women (because of the possibility of gestational hypertension which may resolve after delivery), newly diagnosed patients as well as the physically and mentally incapacitated [27].

\section{Measures}

After informed written consent, a standardized quantitative assessment tool was used to collect data concurrently from the hypertensive patients attending $\mathrm{KBTH}$ and KATH between May and October, 2012. The information gathered covered three areas: i) demographic characteristics; ii) anxiety, depression and stress measures using the Depression Anxiety Stress Scale (DASS) - 21 [28]; iii) medication adherence behaviour using the Morisky Medication Adherence Scale [29]; and iv) the Spiritual Perspective Scale [30]. Participants were asked about their age, sex, place of residence, religious affiliation, marital status, educational level, and duration of hypertensive diagnosis.

The DASS is a 21 item self-report inventory that measures the negative emotional states of depression, anxiety and stress. Each of the three scales comprised seven items with related content. The depression subscale assessed dysphoria, hopelessness, devaluation of life, self-depreciation, and lack of interest/involvement, anhedonia, and inertia. The anxiety subscale measured autonomic arousal, skeletal muscle effects, situational anxiety, and subjective experience of anxious affect. The stress subscale measured relaxation difficulty, nervous arousal, agitation, irritability and impatience. Participants were requested to use a 4-point severity/frequency scale to rate the extent to which they had experienced each negative state over the past week. Reliability for the three scales is 0.71 for depression, 0.79 for anxiety and 0.81 for stress [28]. The DASS anxiety subscale has a correlation coefficient of 0.81 with the Beck Anxiety Inventory whereas the DASS depression subscale had 0.74 with the Beck Depression Inventory [31,32].

The MMAS is an 8-item scale used to measure medication adherence behavior in hypertensive patients and responses are categorized as low adherence $(<6)$, medium adherence $(6-<8)$, and high adherence (8). Low and moderate scores were grouped as poor adherence levels [33].

The ten-item SPS measured the belief perceptions of participants relating to spiritually-related interactions. Scores above or below the mean respectively represented high and low spiritual involvement. The SPS has consistently been reliable with Cronbach's alpha above 0.90 [34]. 


\section{Analysis}

The data gathered from the study were analyzed with the Statistical Package for Social Sciences (SPSS) version 20. Descriptive statistics were used to represent the characteristics of participants. Anxiety, depression and stress, and medication adherence as well as the level of spirituality were evaluated using chi-square tests and logistic regression models.

\section{Ethics}

Ethical clearance from the institutional ethics committees for $\mathrm{KBTH}$ and KATH were obtained before conducting the study. The ethical approval codes are NMIMR-IRB CPN 044/10-11and CHRPE/AP/022/12 respectively.

\section{Results and discussions}

\section{Sample characteristics}

A summary of the sample characteristics (mean and standard deviation) of the hypertensive patients are presented in Table 1 . Approximately $63 \%$ were women, $33 \%$ were 50 to 59 years old, $64 \%$ were married, $90 \%$ were Christians and $54 \%$ had a minimum of a secondary school education. Of these approximately $80 \%$ had had hypertension for $\geq 10$ years, $42 \%$ had co-morbidities and diabetes accounted for $60 \%$ of these. Anxiety, depression and stress were not reported in the co-morbid health conditions. This is to be expected as negative emotions are usually not included in the co-morbidities reported by patients [35]; and may partly be due to the lack of adequate medical information being given to the patients. This finding is however interpreted bearing in mind the limitation that those co-morbidities were self-reported and not obtained from the clinicians or from the patients' health records.

\section{Anxiety and adherence}

Anxiety was common among 225 (57\%) of the hypertensive patients. This result corroborates the high prevalence of anxiety found among hypertensive patients in varied countries such as South Africa, China and Argentina [10,36,37]; thus showing the presence of anxiety in hypertension in spite of cultural variability. Anxiety in hypertension could result in a higher risk of morbidity and mortality as a result of hastened cardiovascular events [38]. Although it was not measured in the scope of the present study, the anxiety may, in part, be specifically related to the medications or to the chronic health condition [39]. Approximately $93 \%$ of participants poorly adhered to their anti-hypertensive medications (Table 1). Although previous studies had correlated anxiety and medication adherence [12,14-16] the present study did not observe any significant association between anxiety and adherence $\left(x^{2}=3.887, p=0.421\right),[(\mathrm{OR})=1.6(0.7-3.66), p=0.262]$;
Table 1 Characteristics of study sample

\begin{tabular}{|c|c|c|}
\hline Variable & Frequency & Percentage \\
\hline \multicolumn{3}{|l|}{ Sex } \\
\hline Male & 149 & 37.25 \\
\hline Female & 251 & 62.75 \\
\hline \multicolumn{3}{|l|}{ Age } \\
\hline$<20$ & 1 & 0.25 \\
\hline $20-29$ & 12 & 3.00 \\
\hline $30-39$ & 20 & 5.00 \\
\hline $40-49$ & 71 & 17.75 \\
\hline $50-59$ & 130 & \\
\hline $60-69$ & 105 & 26.25 \\
\hline$\geq 70$ & 61 & 15.25 \\
\hline \multicolumn{3}{|l|}{ Marital status } \\
\hline Single & 39 & 9.75 \\
\hline Married & 254 & 63.50 \\
\hline Widowed & 73 & 18.25 \\
\hline Divorced/separated & 25 & 6.25 \\
\hline Co-habiting & 9 & 2.25 \\
\hline \multicolumn{3}{|l|}{ Education } \\
\hline No formal & 48 & 12.00 \\
\hline Primary & 33 & 8.25 \\
\hline Secondary & 217 & 54.25 \\
\hline Tertiary & 102 & 25.50 \\
\hline \multicolumn{3}{|l|}{ Religious affiliation } \\
\hline Christian (spiritual) & 18 & 4.50 \\
\hline Christian (Charismatic/Pentecostal) & 166 & 41.50 \\
\hline Christian (Orthodox) & 174 & 43.50 \\
\hline Muslim & 20 & 5.00 \\
\hline African Traditional Religion & 4 & 1.00 \\
\hline Other & 18 & 4.50 \\
\hline \multicolumn{3}{|c|}{ Number of years of having hypertension } \\
\hline$\leq 10$ years & 318 & 79.50 \\
\hline $11-20$ years & 49 & 12.25 \\
\hline $21-30$ years & 20 & 5.00 \\
\hline $31-40$ years & 12 & 3.00 \\
\hline $41-50$ years & 1 & 0.25 \\
\hline \multicolumn{3}{|l|}{ Level of adherence } \\
\hline Low & 323 & 80.75 \\
\hline Moderate & 50 & 12.50 \\
\hline High & 27 & 6.75 \\
\hline
\end{tabular}

yet our findings on the prevalence of anxiety calls for clinicians to take critical action in addressing the negative emotional needs of anxious hypertensive patients (Tables 2, 3 and 4). 
Table 2 Distribution of degree of symptoms of depression, anxiety and stress

\begin{tabular}{llllll}
\hline Emotional & Normal & Mild & Moderate & Severe & Extremely severe \\
\hline Depression & N (\%) & N (\%) & N (\%) & N (\%) & N (\%) \\
Anxiety & $358(89.50)$ & $25(6.25)$ & $12(3.00)$ & $4(1.00)$ & $1(0.25)$ \\
Stress & $129(32.25)$ & $46(11.50)$ & $140(35.00)$ & $44(11.50)$ & $41(10.25)$ \\
\hline A & $259(64.75)$ & $59(14.75)$ & $52(13.00)$ & $26(6.50)$ & $4(1.00)$ \\
\hline
\end{tabular}

A high number of patients experienced moderate to extremely severe symptoms of anxiety (225), followed by stress (82) and depression (17).

\section{Depression and adherence}

Moderate to extremely severe levels of depressive symptoms which merit clinical attention were found in 17 (4\%) study participants (Table 2). This information is vital because of the increasing impact of depression on the global disease burden [17]. Yet, depression among hypertensive patients is usually not diagnosed [35]. As a consequence such patients may be denied comprehensive clinical care which takes their mental health into consideration. Contrary to other studies which observed participants with depression exhibiting a higher likelihood of medication non-adherence $[16,20,40]$, this association was not observed in the current study $\left(x^{2}=\right.$ 0.004, $p=0.950$ ) which draws the same conclusion as studies by Schweitzer et al. [14] and Corvera-Tindel et al. [22]. These studies showed no relationship between the two variables among patients with chronic heart failure. The outcome of a relationship between depression and non-adherence is likely to be inconclusive due to the small number of participants in this study exhibiting symptoms of depression. However, it is essential for clinicians to pay attention to these negative emotional symptoms because overlooking them may further decrease attempts to manage the global burden of chronic diseases.

\section{Stress and adherence}

Studies on emotional determinants of medication adherence have focused primarily on anxiety and depressive symptoms; however significant stressful events have been reported to be responsible for hypertension [41,42]. We reported 82 patients $(20 \%)$ exhibiting moderate to severe high scores of stress symptoms which may require clinical attention and management (Table 2). Similar to earlier studies on HIV/AIDS [24] and acute coronary syndrome [25], stress was associated with medication non-adherence

Table 3 Relationship between negative emotional characteristics and medication non-adherence

\begin{tabular}{lll}
\hline Variable & Chi-square & $\boldsymbol{p}$-value \\
\hline Depression & 0.004 & 0.950 \\
Anxiety & 3.887 & 0.421 \\
Stress & 5.936 & 0.037 \\
\hline
\end{tabular}

At $p<0.05$, stress and not depression and anxiety significantly related with medication non-adherence. among the study participants $\left(x^{2}=5.936, p=0.037\right)$. The patients who were stressed were more likely to be nonadherent than those who had no or low stress levels $[(\mathrm{OR})=2.42(1.06-5.5), p=0.035]$. A probable explanation is that patients showing stress symptoms may be more susceptible to the negative effects of their medications and thus may discontinue taking them. This observation further supports the need for health providers in this area to pay particular attention to medication adherence in patients who are stressed or those who could potentially be affected by stress.

\section{Relationship between spirituality and anxiety, depression} and stress

Spirituality showed a significant association with lower levels of anxiety $\left(x^{2}=13.352, p=0.010\right)$, depression $\left(x^{2}=\right.$ $6.205, p=0.045)$ and stress $\left(x^{2}=14.833, p=0.001\right)$ (Table 5). These strong spiritual attributes may have enabled patients cope better with the emotional problems of having a chronic condition like hypertension. Greater spiritual well-being has been found to be associated with fewer symptoms of anxiety, depression and stress [43-46]. Most of these studies related to terminally ill patients yet, the outcome from our study has demonstrated a confirmation of the alleviating role of spirituality in emotional experiences that can be applicable to hypertensive patients and by extension, patients with other chronic conditions.

Some limitations are acknowledged. First, this study was conducted in tertiary hospitals only, thus the views of patients with hypertension in Ghana who seek medical care from other healthcare facilities were not obtained. Second, the use of a subjective measure of medication adherence may give wrong adherence estimations. Future studies could supplement patients' report on adherence with objective assessments of adherence.

Table 4 A logistic regression model for negative emotional symptoms and medication non-adherence

\begin{tabular}{llll}
\hline Variable & OR & $\mathbf{9 5 \% ~ C l}$ & $\boldsymbol{p}$ value \\
\hline Anxiety symptoms (present: ref absent) & 1.6 & $0.7-3.66$ & 0.262 \\
Depressive symptoms (present: ref absent) & 0.81 & $0.1-6.29$ & 0.837 \\
Stress symptoms (present: ref absent) & 2.42 & $1.06-5.5$ & 0.035 \\
\hline
\end{tabular}

Adjusted for demographic and clinical characteristics. 
Table 5 Relating spirituality with depression, anxiety and stress symptoms experienced by hypertensive patients

\begin{tabular}{|c|c|c|c|c|c|c|}
\hline \multirow{2}{*}{ Variable } & \multicolumn{2}{|c|}{ Depression } & \multicolumn{2}{|c|}{ Anxiety } & \multicolumn{2}{|l|}{ Stress } \\
\hline & $\overline{X^{2}}$ & $p$ value & $x^{2}$ & $p$ value & $x^{2}$ & $p$ value \\
\hline Spirituality & 6.205 & 0.045 & 13.352 & 0.010 & 14.833 & 0.001 \\
\hline
\end{tabular}

\section{Conclusions}

Patients with hypertension manifested symptoms of anxiety, depression and stress. This implies that the patient's hypertensive state and perhaps the need for adherence to the anti-hypertensive medications placed psychological demands on their health. Thus, although hypertension could be viewed in itself as a biomedical problem, patients' experiences with the demands of living as hypertensives resulted in mental health problems. This illustrates the link between biomedical problems and the development of psychological disorders. Further, spirituality helped patients cope with the emotional burden of having hypertension; a chronic disease. Therefore, the need to adopt a multi-faceted perspective towards health delivery in Ghana becomes real in the purview of these findings. The involvement of clinicians, pharmacists, clinical/health psychologists, religious leaders, and nurses thus becomes important in alleviating the problem of non-adherence and invariably improving the quality of life outcomes of hypertensive patients. Attention could be directed toward the use of spirituality as a possible mechanism by which negative emotions are managed among hypertensive patients.

\section{Competing interests}

The authors declare that they have no competing interest.

\begin{abstract}
Authors' contributions
IK was involved with research concept, data collection, data analysis, interpretation of results, and writing of manuscript. FO and SD contributed to the research concept and interpretation of results. All authors reviewed and approved the final manuscript.
\end{abstract}

\footnotetext{
Acknowledgements

The authors wish to thank the hypertensive patients who participated in this study as well as the staff of KBTH and KATH. For their technical support, the authors are grateful to Dr. Joseph Osafo and Dr. Asamoah Kusi. This research was partially funded by the African Doctoral Dissertation Research Fellowship offered by the African Population and Health Research Center (APHRC) in partnership with the International Development Research Centre (IDRC) as well as the University of Ghana Faculty Development Grant by Office of Research, Innovation and Development (ORID).

Author details

${ }^{1}$ Department of Clinical and Social Pharmacy, Faculty of Pharmacy and Pharmaceutical Sciences, Kwame Nkrumah University of Science and Technology, Kumasi, Ghana. ${ }^{2}$ Department of Pharmacy Practice and Clinical Pharmacy, University of Ghana School of Pharmacy, College of Health Sciences, Legon, Ghana. ${ }^{3}$ Department of Psychology, University of Ghana, Legon, Ghana.
}

Received: 6 May 2014 Accepted: 19 June 2014

Published: 21 June 2014

\section{References}

1. Lim SS, Vos T, Flaxman AD, Danaei G, Shibuya K, Adair-Rohani H, Amann M, Anderson HR, Andrews KG, Aryee M, Atkinson C, Bacchus LJ, Bahalim AN, Balakrishnan K, Balmes J, Barker-Collo S, Baxter A, Bell ML, Blore JD, Blyth F, Bonner C, Borges G, Bourne R, Boussinesq M, Brauer M, Brooks P, Bruce NG, Brunekreef B, Bryan-Hancock C, Bucello C, et al: A comparative risk assessment of burden of disease and injury attributable to 67 risk factors and risk factor clusters in 21 regions, 1990-2010: a systematic analysis for the Global Burden of Disease Study 2010. Lancet 2012, 380(9859):2224-2260.

2. World Health Organization: STEPS Fact Sheet. Brazzaville: WHO AFRO; 2008.

3. World Health Organization: Global Status Report on Non-communicable Diseases. Geneva: WHO Library Cataloguing-in-Publication Data; 2010:WT 500.

4. Bosu W: Epidemic of hypertension in Ghana: a systematic review. BMC Public Health 2010, 10:418.

5. Adedoyin R, Mbada C, Balogun M, Martins T, Adebayo R, Akintomide A, Akinwusi P: Prevalence and pattern of hypertension in a semiurban community in Nigeria. Eur J Cardiovasc Prev Rehabil 2008, 15:683-687.

6. Tesfaye F, Byass P, Wall S: Population based prevalence of high blood pressure among adults in Addis Ababa: uncovering a silent epidemic BMC Cardiovasc Disord 2009, 9:39.

7. Twagirumukiza M, De Bacquer D, Kips JG, de Backer G, Stichele RV, Van Bortel LM: Current and projected prevalence of arterial hypertension in sub-Saharan Africa by sex, age and habitat: an estimate from population studies. J Hypertens 2011, 29(7):1243-1252.

8. Kearney PM, Whelton M, Raynolds K, Murtner P: Global trends of hypertension analysis of worldwide data. Lancet 2005, 365:217-223.

9. DeJean D, Giacomini M, Vanstone M, Brundisini F: Patient experiences of depression and anxiety with chronic disease: a systematic review and qualitative meta-synthesis. Ont Health Technol Assess Ser 2013, 13(16):1-33.

10. Vetere G, Ripaldi L, Ais E, Korob G, Kes M, Villamil A: Prevalence of anxiety disorders in patients with essential hypertension. Vertex 2007, 18(71):20-25.

11. Duvdevany I, Cohen M, Minsker-Valtzer A, Lorber M: Psychological correlates of adherence to self-care, disease activity and functioning in persons with systemic lupus erythematosus. Lupus 2011, 20:14-22.

12. De Jong MJ, Moser DK, Chung ML, Wu J: Non-adherence to prescribed medications mediates the link between anxiety and event-free survival in patients with heart failure. Circulation 2008, 118:S_769-S_770.

13. Kaveh K, Kimmel P: Compliance in hemodialysis patients: multidimensional measures in search of a gold standard. Am J Kidney Dis 2001, 37(2):244-266.

14. Schweitzer R, Head KB, Dwyer J: Psychological factors and treatment adherence behavior in patients with chronic heart failure. J Cardiovasc Nurs 2007, 22(1):76-83.

15. Walsemann KM, Perez AD: Anxiety's relationship to inconsistent use of oral contraceptives. Health Educ Behav 2006, 33:197.

16. Kim HK, Park JH: Differences in adherence to antihypertensive medication regimens according to psychiatric diagnosis: results of a Korean population-based study. Psychosom Med 2010, 72(1):80-87.

17. Vettath RE, Reddy YN, Dutta S, Singh Z, Mathew M, Abraham G: A multicenter cross-sectional study of mental and physical health depression in MHD patients. Indian J Nephrol 2012, 22(4):251-256.

18. Scalco AZ, Scalco MZ, Azul JB, Lotufo Neto F: Hypertension and depression. Clinics 2005, 60(3):241-250.

19. DiMatteo $M$, Lepper $H$, Croghan $T$ : Depression is a risk factor for noncompliance with medical treatment: meta-analysis of the effects of anxiety and depression on patient adherence. Arch Intern Med 2000 , 160:2101-2107.

20. Etienne M, Hossain M, Redfield R, Stafford K, Amoroso A: Indicators of adherence to antiretroviral therapy treatment among HIV/AIDS patients in 5 African countries. J Int Assoc Provid AIDS Care 2010, 9:98.

21. Sung K: Factors associated with depressive symptoms in low-income, older Korean women with hypertension. Nurs Health Sci 2011, 13(3):309-315.

22. Corvera-Tindel T, Doering LV, Gomez T, Dracup K: Predictors of noncompliance to exercise training in heart failure. J Cardiovasc Nurs 2004, 19(4):269-277.

23. Hotopf M, Henderson M, Kuh D: Stress and mortality. Am J Epidemiol 2008, 168:5.

24. Leserman J: Role of depression, stress, and trauma in HIV disease progression. Psychosom Med 2008, 70:539-545. 
25. Molloy GJ, Perkins-Porras L, Strike PC, Steptoe A: Social networks and partner stress as predictors of adherence to medication, rehabilitation attendance, and quality of life following acute coronary syndrome. Health Psychol 2008, 27(1):52-58.

26. Kulkarni S, O'Farrell I, Erasi M, Kochar MS: Stress and hypertension. WMJ 1998, 97(11):34-38.

27. Kretchy I, Owusu-Daaku F, Danquah S: Spiritual and religious beliefs: do they matter in the medication adherence behaviour of hypertensive patients? Biopsychosoc Med 2013, 7:15.

28. Lovibond SH, Lovibond PF: Manual for the Depression Anxiety Stress Scales. Sydney: Psychology Foundation; 1995

29. Krousel-Wood MA, Islam T, Webber LS, Re RN, Morisky DE, Muntner P: New medication adherence scale versus pharmacy fill rates in seniors with hypertension. Am J Manag Care 2009, 15(1):59-66.

30. Reed P: Spirituality and well-being in terminally III hospitalized adults. Res Nurs Health 1987, 10:335-344.

31. Crawford JR, Henry JD: The Depression Anxiety Stress Scales (DASS): normative data and latent structure in a large non-clinical sample. Brit J Clin Psychol 2003, 42:111-131.

32. Lovibond PF, Lovibond SH: The structure of negative emotional states: Comparison of the Depression Anxiety Stress Scales (DASS) with the beck depression and anxiety inventories. Behav Res Ther 1995, 33:335-342.

33. Kretchy IA, Owusu-Daaku F, Danquah S: Patterns and determinants of the use of complementary and alternative medicine: a cross-sectional study of hypertensive patients in Ghana. BMC Complement Altern Med 2014, 14:44.

34. Jesse DE, Reed RG: Effects of spirituality and psychosocial well-being on health risk behaviors in Appalachian pregnant women. JOGNN 2004 33:739-747.

35. Bane C, Hughes CM, McElnay JC: The impact of depressive symptoms and psychosocial factors on medication adherence in cardiovascular disease. Patient Educ Couns 2006, 60:187-193.

36. Grimsrud A, Stein D, Seedat S, Williams D, Myer L: The association between hypertension and depression and anxiety disorders: results from a nationally representative sample of South African adults. PLoS One 2009, 4:2.

37. Han J, Yin XM, Xu F, Hong X, Liang YQ, Wang ZY: A case-control study on depression and anxiety in hypertensive patients. Chin J Epid 2009, 29(2):125-127.

38. Roest AM, Martens EJ, de Jonge P, Denollet J: Anxiety and risk of incident coronary heart disease: a meta-analysis. J Am Coll Cardiol 2010, 56:38-46.

39. Kasahara S, Ohno Y, Sugo A: A report on medication adherence among outpatients. Jpn J Publ Health 2002, 49(12):1259-1267.

40. Krousel-Wood MA, Frohlich ED: Hypertension and depression: co-existing barriers to medication adherence. J Clin Hypertens 2010, 12(7):481-486.

41. Higginbottom G: "I didn't tell them. Well, they never ask": lay understandings of hypertension and their impact on chronic disease management: implications for nursing practice in primary care. $J$ Nurs Res 2008, 13:89-99.

42. Spencer J, Phillips E, Ogedegbe G: Knowledge, attitudes, beliefs, and blood pressure control in a community-based sample in Ghana. Ethnic Dis 2005, 15:748-752.

43. Koenig HG: An 83-year-old woman with chronic illness and strong religious beliefs. JAMA 2002, 288:487-493.

44. McClain C, Rosenfeld B, Breibart W: Effect of spiritual well-being on end-of-life despair in terminally-ill cancer patients. Lancet 2003, 361:1603-1607.

45. McCoubrie R, Davies A: Is there a correlation between spirituality and anxiety and depression in patients with advanced cancer? Support Care Cancer 2006, 14:379-385.

46. Rodin G, Lo C, Mikulincer M, Donner A, Gagliese L, Zimmermann C: Pathways to distress: the multiple determinants of depression, hopelessness, and the desire for hastened death in metastatic cancer patients. Soc Sci Med 2009, 68:562-569.

doi:10.1186/1752-4458-8-25

Cite this article as: Kretchy et al: Mental health in hypertension: assessing symptoms of anxiety, depression and stress on anti-hypertensive medication adherence. International Journal of Mental Health Systems $20148: 25$.

\section{Submit your next manuscript to BioMed Central and take full advantage of:}

- Convenient online submission

- Thorough peer review

- No space constraints or color figure charges

- Immediate publication on acceptance

- Inclusion in PubMed, CAS, Scopus and Google Scholar

- Research which is freely available for redistribution

Submit your manuscript at www.biomedcentral.com/submit
C Biomed Central 